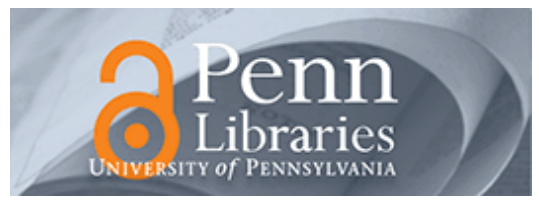

University of Pennsylvania

ScholarlyCommons

Operations, Information and Decisions Papers

Wharton Faculty Research

$7-2008$

\title{
Cost Convergence in the US Airline Industry: An Analysis of Unit Costs 1995-2006
}

Gerassimos Tsoukalas

Peter Belobaba

William Swelbar

Follow this and additional works at: https://repository.upenn.edu/oid_papers

Part of the Business Administration, Management, and Operations Commons, and the Marketing Commons

\section{Recommended Citation}

Tsoukalas, G., Belobaba, P., \& Swelbar, W. (2008). Cost Convergence in the US Airline Industry: An Analysis of Unit Costs 1995-2006. Journal of Air Transport Management, 14 (4), 179-187. http://dx.doi.org/ 10.1016/j.jairtraman.2008.04.005

This paper is posted at ScholarlyCommons. https://repository.upenn.edu/oid_papers/42

For more information, please contact repository@pobox.upenn.edu. 


\title{
Cost Convergence in the US Airline Industry: An Analysis of Unit Costs
}

\section{5-2006}

\begin{abstract}
Recent changes in the strategies of US airlines have led to a convergence of unit costs between the network legacy carriers and low-cost carriers. We develop a methodology for breaking down operating cost data reported by the airlines and argue that certain cost categories must be excluded to make a valid comparison between the carrier groups. We find significant evidence of convergence in unit costs excluding fuel and transport-related expenses, and labor unit costs in particular. While network legacy carriers have improved cost efficiency through dramatic labor cost reductions and longer stage length flying, low-cost carriers labor unit costs continue to increase as these former new entrant airlines mature.
\end{abstract}

\section{Keywords}

airline operating costs, unit costs, legacy airlines, low-cost carriers

\section{Disciplines}

Business Administration, Management, and Operations | Marketing 


\title{
Cost Convergence in the US Airline Industry: An Analysis of Unit Costs 1995-2006
}

\author{
Gerassimos Tsoukalas \\ Peter Belobaba* \\ William Swelbar \\ MIT Global Airline Industry Program \\ 77 Mass. Ave., Room 33-215 \\ Cambridge, MA 02139
}

December 2007

Revised April 2008

\begin{abstract}
Recent changes in the strategies of US airlines have led to a convergence of unit costs between the Network Legacy Carriers (NLCs) and Low Cost Carriers (LCCs). We develop a methodology for breaking down operating cost data reported by the airlines and argue that certain cost categories must be excluded to make a valid comparison between the carrier groups. We find significant evidence of convergence in unit costs excluding fuel and transport-related expenses, and labor unit costs in particular. While NLCs have improved cost efficiency through dramatic labor cost reductions and longer stage length flying, LCC labor unit costs continue to increase as these former new entrant airlines mature.
\end{abstract}

*Corresponding Author:

Tel: +1-617-253-7573; Fax: +1-617-452-2996; e-mail: belobaba@mit.edu 


\section{Introduction}

The US airline industry has been in a financial crisis for much of this new century, a crisis exacerbated by the terror attacks of 9/11. The rapid growth of Low-Cost Carriers (LCCs) in the US domestic market presented the traditional Network Legacy Carriers (NLCs) with intense price competition, as the LCCs fully exploited the significant cost advantage they enjoyed at the time. High costs and a declining revenue environment pushed four out of six NLCs ${ }^{1}$ into bankruptcy. Whether under bankruptcy protection (United, US Airways, Delta and Northwest) or under the threat of bankruptcy (American and Continental), the NLCs have made efforts to reduce their cost structures and to improve their labor and aircraft productivity. These significant cost cuts contributed to the industry achieving modest profitability in 2006, for the first time since 2000.

This paper examines the extent to which the NLCs have been able to reduce the unit cost gap that historically has existed between them and their low-cost rivals. We examine the evolution of unit operating costs in the US airline industry from 1995 to 2006 and the underlying forces driving change. We conduct an in depth analysis of US DOT Form 41 financial and operating cost data to show that the NLC’s cost-cutting strategy has resulted in substantial cost convergence between them and their low-cost counterparts. While a superficial comparison of total unit costs might suggest that the gap between NLCs and LCCs has increased since 2000, we present a breakdown of unit costs that clearly demonstrates that significant convergence has occurred.

\footnotetext{
${ }^{1}$ The term "Network Legacy Carriers" refers to the six largest traditional US carriers: American, Continental, Delta, Northwest, United and US Airways
} 
In Section 2, we provide a brief review of relevant literature. Section 3 describes the dataset that we have used and explains our approach for determining airline group selections, the logic for excluding certain components of reported cost data in our comparisons, and the methodology used to aggregate the unit cost metrics. Section 4 presents the analysis of unit costs and is broken down into two parts: We first compare aggregate measures of unit costs between the NLC and LCC groups. We then take a look at individual airlines in both groups and provide more detail to help explain the observed convergence of unit costs. Section 5 summarizes the findings and discusses some of the implications of our analysis.

\section{Literature Review}

The focus of most studies of airline cost performance has been on comparisons of unit cost, specifically Cost per Available Seat Mile, or “CASM”. CASM is defined as total airline operating expense over available seat miles (ASMs) produced. In turn, ASMs equal the number of available seats flown by the airline, multiplied by the total distance flown by its aircraft.

The focus of previous studies of airline operating cost performance has evolved with historical changes in the airline industry. Shortly after deregulation of domestic airline markets in the United States, Jordan (1982) undertook an extensive study of the cost and productivity performance of Canadian airlines. In the US, early studies of the impacts of deregulation included Meyer et al (1981), which looked for trends in airfares and service to small communities in addition to airline productivity and unit costs. Morrison and Winston (1986) established statistical relationships between airline operating cost variables and financial performance, with a focus on fuel and labor costs. 
Oum and Yu (1998) published an extensive study of productivity and cost competitiveness of world airlines, including the consideration of various financial indicators. And, in the US, the Government Accountability Office (2004) issued a report with a title that very clearly describes the study’s principal conclusion: “Legacy Airlines Must Further Reduce Costs to Restore Profitability”.

In our comparative analysis of unit operating costs, we focus on the categorization of airline operating costs. Holloway (2003) provides an overview of the various types of schemes that have been established to categorize costs in the airline business. Doganis (2006) also discusses airline cost categorization, but concentrates more specifically on the importance of labor costs. He argues that labor costs along with fuel costs are the two most important cost categories because, when combined, they usually account for about $50 \%$ of an airline's total costs. The breakdown of costs into labor vs. non-labor is of particular relevance to the adjustments and comparisons we propose in the following section.

It should be noted that, although both researchers and airline managers often focus on the control of operating expenses and unit costs as an important strategy in competitive airline markets, low costs on their own do not guarantee profitability. Revenues are just as critical to profitability and it could be argued that the recent financial crisis of US airlines was caused in large part by extreme price competition that lowered industry revenues overall. Our focus on unit costs excludes the impacts of price competition and revenues on airline industry profitability. However, it is clear that, without their lower cost structures, LCCs would not have been able to offer such low 
fares in US domestic markets. As in most industries, low-cost producers have an inherent competitive advantage.

\section{Dataset and Methodology}

The primary source of data used in our analysis consists of Form 41 filings to the US Department of Transportation. We used Form $41 \mathrm{P}$ and B schedules filed by airlines to extract the financial and operating data, as shown in Figure 1. We limited our study to 1995-2006 because this interval represents three distinct periods of the airline industry cycle: The "golden 90s" from 1995 to 2000 when the industry experienced record profitability; the restructuring period from 2001 to 2005; and a return to profitability in 2006.

\section{Airline Group Selection}

The Network Legacy Carriers (NLCs) are traditional airlines with comprehensive hub-and-spoke networks comprised of regional domestic, mainline domestic and international services. In contrast, Low Cost Carriers (LCCs) airlines that have smaller networks with a hybrid of hub and spoke and point-to-point network attributes, simpler service levels, and a lower overall cost structure that allows them to offer significantly lower fares. Although these definitions seem relatively straightforward, in practice not all airlines can be easily categorized as an NLC or LCC.

For example, Southwest has always been considered a LCC and for good reason they pioneered the concept of maintaining low operating costs in order to deliver a low fare product concept. Still, Southwest’s original point-to-point network structure has evolved into a complex hybrid of point-to-point and multi-hub operations. There are also 
airlines that fall somewhere between these two definitions. Alaska Airlines does not fit clearly into either category. Its cost structure is somewhat lower than some NLCs, yet higher than most LCCs and its network structure falls somewhere in between the two types of carriers. For this reason, we decided not to include Alaska in our analysis of these two distinct sectors.

The 2005 merger of US Airways and America West resulted in a single airline that kept the US Airways name. So far, the carriers have obtained a single operating certificate, but their Form 41 data was still filed separately through 2006. For our analysis, we combined both airlines into one and included them in the NLC group under the single name US Airways (US).

Our breakdown of airlines is shown in Table 1 . These 12 carriers account for the majority of the US airline market share (as measured by RPMs). In 2006, the NLCs accounted for roughly $70 \%$ of US industry traffic and the LCCs accounted for another $18 \%^{2}$.

\section{Unit Cost (CASM) Adjustments}

In making valid comparisons of cost efficiency between NLCs and LCCs, it is necessary to make adjustments to the unit costs reported by the carriers to eliminate factors that can distort the comparisons. We identified two factors that can distort unit cost comparisons among airlines.

Transport related expenses for the most part represent payments made by airlines to regional carriers to provide services to smaller cities on their behalf, providing incremental connecting traffic and revenue to the mainline carrier. These payments

\footnotetext{
${ }^{2}$ Aviation Daily, US Industry Traffic Market Share, Eclat Consulting, McGraw-Hill, Friday, August 18, 2006.
} 
clearly do not represent actual "operating expenses" related to the provision of the capacity (ASMs) output of the mainline carrier. Since the ASMs of the regional carrier are not included in the denominator of unit costs, the payments made to regional carriers should not be included in the numerator if we are comparing cost efficiency across airlines.

Excluding Transport Related Expenses from unit cost comparisons is particularly important in comparisons of NLCs and LCCs, given that LCCs have generally not been active in employing regional partners for traffic feed. The inclusion of transport related expenses in calculating NLC CASM can lead to a significant distortion that favors LCC unit cost measurements. Although the Legacy carriers incur these transport related costs, the ASMs produced from these outsourcing activities are not reported as part of the mainline operations, leading to what appear to be higher CASM for the NLCs. This distortion has become greater since 2002, when accounting changes required airlines to account fully for the fees paid to their regional partners for capacity being purchased, increasing the proportion of Transport Related Expenses dramatically for the NLCs.

Fuel expenses are usually included in unit cost comparisons, based on the assumption that all airlines are subject to the same fuel price environment. Although this has been the case historically, the emergence of financial hedging instruments has provided new ways for airlines to control, or manage, their fuel expenses. The most striking example is that of Southwest, which locked in the price of its fuel purchases thereby eliminating a great deal of its exposure to the fuel price surge during 2005 and 2006. The increased use of fuel hedging means that airlines are no longer on a level playing field when it comes to reported fuel costs. We believe that these financial 
decisions should not be included in our cost comparisons - we thus also removed fuel expenses from some of our comparisons.

After removing transport related and fuel expenses from total costs, we can break down the remaining costs into two categories:

Labor costs include total salaries, all social benefits and other costs, paid out to employees either directly or indirectly. This category gives an indication of cost of the labor inputs in an airline’s total cost structure.

Non-labor costs include everything that is not part of transport related, fuel or laborrelated costs. It does include outsourcing which, of course, can have a labor component. This category contains cost items that provide a good gauge of how management influences “controllable costs” in other areas of its operation. A summary of our approach for adjusting CASM is presented in Figure 2.

\section{Aggregation of Cost Measures}

To report aggregate measures for each airline group, we used weighted averages. We summed the quarterly numbers extracted from Form 41 to produce annual totals, and then summed the data for each airline group (NLC vs. LCC) before computing cost measures using these aggregate results within each group. For example, the aggregate total unit cost of the NLC group is given for year “ $\mathrm{j}$ ” as follows:

$$
C A S M_{N L C s}^{\text {yearj }}=\frac{\sum_{i=1}^{6} \text { OpExpenses }_{i}^{j}}{\sum_{i=1}^{6} A S M_{i}^{j}}
$$

where $\mathrm{i}=1, \ldots, 6$ is the set of Legacy carriers and “j” represents year " $\mathrm{j}$ ” of our time period $(j=1995, \ldots, 2006)$. This formula is equivalent to a weighted average on ASMs of each 
individual airline for each year “ $\mathrm{j}$ ”. The same computations are repeated for the LCC group of carriers in order to obtain the "LCC" average.

\section{Results of Unit Cost Comparisons}

In this section we present the results of our unit cost analysis, in increasing levels

of detail. The first part examines industry trends by comparing the aggregate unit costs of the NLC and LCC groups. The second part presents trends for individual airlines from both groups to identify which carriers have been the most successful at reducing their unit costs in the labor and non-labor categories.

\subsection{Aggregate Unit Cost Comparison: NLC vs. LCC}

Since 2001, the NLCs have been forced to seek greater efficiency in order to survive one of the worst financial crises in their history. At the same time LCCs have managed to increase their share of the US domestic market with their alternative business models and lower cost structures. This aggregate analysis examines differences in unit costs between the two groups, focusing on the major cost components which include nontransport related costs, non-fuel costs, labor and non-labor costs.

As shown in Figure 3, total CASM increased significantly from 1995 to 2006 for both the NLCs and LCCs. From 1995 to 2000 the difference in CASM remained almost constant at around 2.6 cents per ASM. After 2000, the NLC CASM began to increase faster than LCC CASM, widening the unit cost gap from 2.6 cents per ASM in 2000 to 4.4 cents in 2006. During this time period, the NLCs experienced a 30\% increase in total CASM while LCCs realized only a 15\% increase. Based on this misleading comparison between the two groups, these results erroneously suggest that the groups are diverging 
significantly with respect to total unit costs despite the well-publicized efforts of NLCs to improve cost efficiency.

Figure 4 shows that removing transport-related expenses from the reported unit costs creates a very different view of the gap in CASM between the two groups. From 1995 to 2000 the difference in CASM remains almost constant, as was the case with the unadjusted measure. Since 2000, however, the CASM gap decreased slightly, ending up at 2.0 cents per ASM compared to 2.2 cents per ASM in 2000. These results suggest that the CASM gap between the two groups has remained stable or even diminished in recent years, once the distortions of transport-related expenses are removed.

By removing both fuel and transport-related expenses we obtain a measure of CASM that in our view provides a more consistent cost comparison between the groups. The results for this modified CASM (CASM $\mathrm{exTF}_{\text {) }}$ are shown in Figure 5 and present a

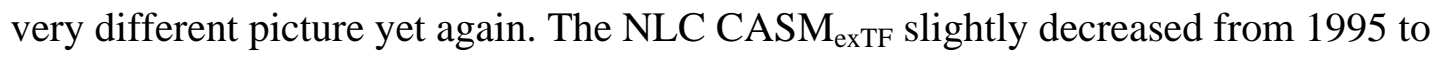
2006 but increased slightly for LCCs. The biggest changes have occurred between 2001

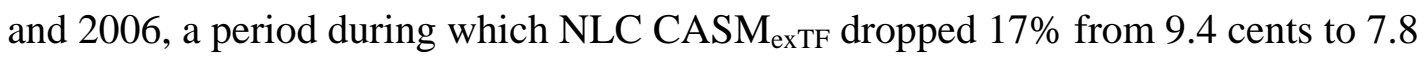

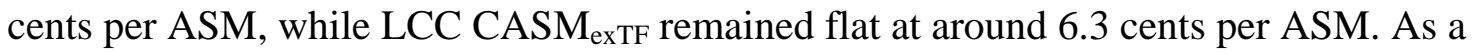
result the difference between the carrier groups decreased from 2.3 cents to 1.3 cents per ASM, a 43\% decrease in the unit cost gap.

The results suggest that fuel and transport-related expenses have been predominant in driving up the reported total unit costs for NLCs since 2000 and that fuel has been the main cause of increased unit costs for LCCs. Once we remove fuel and transport-related expenses, we see significant cost convergence in $\mathrm{CASM}_{\mathrm{exTF}}$ between 
2000 and 2006. In order to identify the underlying forces of this trend we further break down this cost measure into its labor and non-labor components.

In Figure 6, we can see that non-labor $\mathrm{CASM}_{\mathrm{exTF}}$ remained effectively flat from 1995 to 2006 for both groups. The gap in non-labor CASM between the groups remained very stable from 1995 to 2000 at 1 cent per ASM. From 2000 to 2001 the gap widens slightly and then narrows until 2004. From 2004 onward, the gap in non-labor CASM exTF $_{\text {f }}$

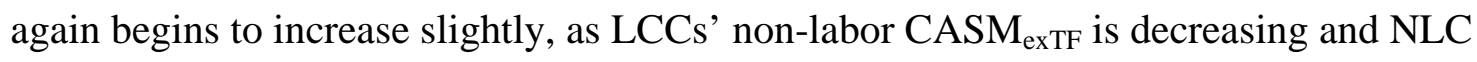
non-labor $\mathrm{CASM}_{\mathrm{exTF}}$ is increasing.

The non-labor $\mathrm{CASM}_{\mathrm{exTF}}$ category includes all remaining costs other than direct labor, fuel and transport-related expenses. In this sense it is a reflection of a company's internal cost structure resulting from a variety of factors such as network structure, fleet type, and outsourcing activity to name a few. It is thus difficult to identify the particular factors that are most responsible for the variations in non-labor CASM $_{\text {extF. However, }}$ given the fact that excluding some variations between 2000 and 2005, the gap between both groups has remained stable, we expect to see the convergence in CASM $\mathrm{exTF}_{\mathrm{e}}$ identified previously to be explained by a convergence in the labor component.

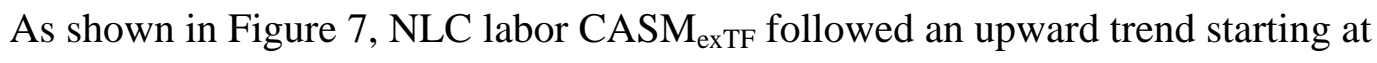
3.5 cents per ASM in 1995 and reached a peak in 2002 at 4.5 cents per ASM. Since 2002, it has been reduced by almost 30\% to 3.3 cents per ASM. On the other hand, LCC labor

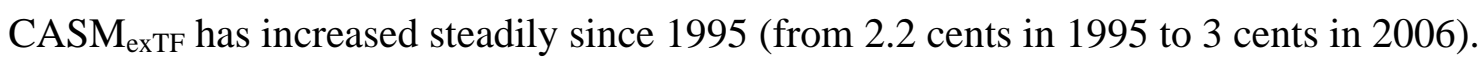
These trends have led to a significant reduction of the gap in labor unit costs between the carrier groups since 2000, from 1.2 cents in 2000 and to just 0.3 cents by 2006. This is 
dramatic evidence of convergence in labor unit costs between NLCs and LCCs over the past 6 years.

The large decrease in labor CASM $_{\text {exTF }}$ for NLCs is a direct result of the costcutting strategies implemented during the recent financial crisis. Bankruptcies and the threat of bankruptcies have played an important role in allowing NLCs to cut their work forces, negotiate lower overall compensation and increase productivity. On the other hand, LCCs have had to deal with increasing seniority and some slowing in their organic growth rates, both of which have contributed to higher unit labor costs. The aggregate results thus show that NLCs have been so effective in cutting their labor costs that they have become competitive in this respect with their LCC rivals. In other words, the LCC advantage can no longer be simply attributed to lower labor costs.

Figure 8 shows that NLCs have gone through a fundamental transformation of their cost structures, particularly their labor cost component. Fuel and transport related expenses have grown from $13 \%$ of unit costs in 1995 to over $40 \%$ of unit costs in 2006 . These increases, as well as the labor cost-cutting strategies, have reduced labor costs to less than $30 \%$ of the total in 2006 . The non-labor cost category has also been reduced from $45 \%$ in 1995 to $30 \%$ in 2006 . These results further support the conclusion that fuel and transport-related expenses have been the main drivers behind the increase in total unit costs shown in Figure 3.

The results for the LCC group in Figure 9 reflect the same impact of fuel prices. The fuel component of total LCC CASM has increased from 15\% in 1995 to around 30\% in 2006. Labor cost proportions have fluctuated throughout the period but remained 
centered on a value of $30 \%$ of total unit costs. The non-labor component of LCC unit cost has thus decreased from 50\% of the total in 1995 to 35\% in 2006.

In summary, our aggregate analysis demonstrates the importance of making certain adjustments to reported unit cost data in order to make valid and consistent comparisons of cost efficiency between the NLC and LCC airline groups. A superficial comparison of unadjusted CASM data would incorrectly suggest that the unit cost gap between NLCs and LCCs has actually increased since 2001 despite the cost cutting efforts of the NLCs. Once we remove transport-related and fuel expenses, we see a substantial convergence of unit costs between the two groups, driven largely by changes in the labor cost component - NLCs have cut labor unit costs by $30 \%$, while LCC labor unit costs continue to increase.

\subsection{Individual Airline Cost Comparisons}

Consistent with our results from the aggregate cost comparisons, by removing fuel and transport-related expenses we see that all NLCs have managed to significantly reduce their unit costs in the most recent 5-year period (Figure 10). The biggest decreases can be seen for US Airways, United and American at 24\% while Continental achieved the lowest decrease at $7 \%$. On average, the NLC group experienced a reduction of $16 \%$ in

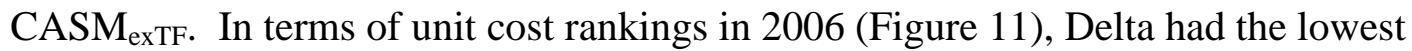
$\mathrm{CASM}_{\mathrm{exTF}}$ in the NLC group (\$0.074) while Northwest was highest at \$0.081. As a group in 2006, the NLCs had an average CASM $_{\text {exTF }}$ of $\$ 0.077 /$ ASM with very small variation within the group.

The LCCs had split results over the same period. While JetBlue, Frontier and AirTran managed to reduce their $\mathrm{CASM}_{\mathrm{exTF}}$, Southwest, ATA and Spirit experienced an 
increase. ATA unit cost increased by $8 \%$, explained by the difficulties the airline was experiencing during its bankruptcy. Spirit's results were substantially worse than the rest

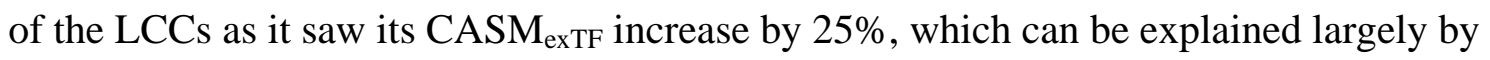
a fleet transformation.

From these results it is clear that the NLCs have in general been more successful at cutting unit costs than their low-cost rivals, pointing towards a changing dynamic of cost convergence between the groups.

\section{Labor Cost Component}

The results shown in Figure 12 reflect a dramatic contrast in labor unit cost trends between NLC and LCC carriers. The most successful NLCs in terms of cutting labor costs were those that went through bankruptcy during that period. Among them, US Airways led the group with a decrease of $39 \%$ in labor unit costs, while American and Continental - the two airlines that did not declare Chapter 11 - still managed 18\% and $11 \%$ decreases, respectively. On average, the NLCs reduced labor CASM by 25\%. In 2006, US Airways had the lowest labor unit cost among NLCs, at just under \$0.029/ASM, while American had the highest labor CASM at \$0.037/ASM.

The LCC picture is quite different. Apart from AirTran and JetBlue who managed to reduce their labor CASM, the rest of the LCCs have experienced significant increases ranging from 4\% at Frontier to 26\% at ATA. The LCC rankings for 2006 have JetBlue with the lowest labor unit costs at $\$ 0.021$ /ASM while the highest of the group is Southwest at \$0.034/ASM. Southwest, which accounts for more than half of the LCC ASMs, has had to deal with the fact that its pilots and staff are becoming more senior and 
demanding commensurately higher wage rates. In fact, Southwest’s labor CASM was higher in 2006 than any NLC, with the exception of American.

These results reflect the underlying forces of cost-convergence discussed in the aggregate analysis. All NLCs have dramatically reduced their labor costs, while LCCs (led by Southwest which represents the largest proportion of LCC ASMs) have had to deal with increased labor costs due to their employees becoming more senior and slowing growth. As a result, in 2006, NLCs had an average labor CASM of \$0.032/ASM while LCCs had an average of \$0.029/ASM. The difference between the groups has been reduced to just 0.3 cents per ASM, all but eliminating the historic LCC labor unit cost advantage.

\section{Non-Labor Cost Component}

Figure 13 summarizes the non-labor CASM changes at individual airlines, and suggests that both groups of carriers have for the most part managed to reduce their nonlabor CASM between 2001 and 2006.

The NLCs have managed to reduce these costs by an average of 9\%. American has made the greatest improvement, achieving a $28 \%$ reduction while Northwest was the only NLC to see an increase (of 5\%), but the results predate any cost decreases being fully realized after emergence from bankruptcy. Further, it is important to note that maintenance costs stemming from a maintenance workers strike at Northwest have been shifted to outsourcing expenses which are included in non-labor costs. A major factor contributing to these non-labor cost reductions is the development of advanced information technology systems and the emergence of internet-based distribution and passenger processing. In absolute terms, the NLC group had average non-labor costs of 
\$0.044\$ASM in 2006 with American lowest at \$0.040 and Northwest highest at

$\$ 0.048 / A S M$.

During the same period LCCs also managed to reduce their non-labor unit costs by an average of 5\%. Frontier was the most successful achieving a $27 \%$ reduction while Spirit was disproportionately unsuccessful, with a 27\% increase. In 2006, the LCCs had an average non-labor CASM of \$0.034/ASM which is still a clear advantage of 1 cent/ASM when compared to their NLC rivals. However, similar to the results for labor CASM, the non-labor CASM is also converging.

The most successful airline at keeping its non-labor CASM low is Southwest. The airline's results stand out from its peers as it is the only LCC to have labor costs at a higher level than non-labor costs in 2006. We can see that during the 2001-2006 period, although Southwest was struggling with increasing labor costs as we saw in the previous section, it did a tremendous job in reducing its non-labor costs. As a result the airline’s $\mathrm{CASM}_{\text {exTF }}$ has remained almost constant.

\subsection{Unit Costs and Stage Length}

Our discussion of the trends in all measures of unit cost would not be complete without some mention of the role of stage length in affecting the unit cost comparisons. Theoretical expectations and empirical results suggest that increasing stage length lowers unit costs, with all else equal, as the increase in operating expenses attributed to longer stage length is less than proportional to the increase in ASMs. Simply stated, longer stage lengths allow the fixed costs of each flight to be spread over more ASMs.

Figure 14 shows just how active all airlines have been in pursuing this fundamental relationship. We plot unit costs vs. stage length in 2000 and 2006 and to 
show the change between these two years for each airline we draw a vector originating in the year 2000 and ending in 2006. It is clear that all airlines have been very active in increasing their stage length during this period, with most of these increases correlating well with lower unit costs of each type examined.

Figure 14 shows that the trends in CASM $_{\text {exTF }}$ are almost uniform across the industry. With the exception of ATA and Spirit, all airlines have managed to decrease their $C A S M_{\text {exTF }}$ while increasing stage length. This is in line with the theoretical expectations and empirical results.

\section{Summary of Results and Conclusion}

In this paper we have shown that during the period 2001-2006, both NLCs and LCCs have gone through a period of fundamental change which has greatly affected their unit costs. During this period, the NLCs focused on downsizing and cost-cutting in an effort to regain profitability. On the other hand, most LCCs sought to accelerate their organic growth and capture significant market share from their NLC peers. However, the LCCs were also facing increasing labor costs driven by an aging fleet and by the fact that their staff was becoming more senior.

A superficial comparison of total unit costs for NLCs and LCCs during the period since 2001 would suggest that, despite the substantial efforts of NLCs to improve productivity and reduce operating costs, the unit cost gap between NLCs and LCCs has increased. Such a conclusion would be incorrect, based on misleading comparisons of cost data that include components that create distortions to unit cost metrics.

After making several adjustments to the unit cost data as reported, we found evidence of substantial convergence in the remaining portions of unit costs between 
NLCs and LCCs. The most dramatic convergence has occurred in labor unit costs, as they have decreased by $25 \%$ for the NLCs while continuing to increase for LCCs. By 2006, the historical labor unit cost advantage that LCCs have had in this category was all but eliminated. Non-labor unit costs also showed decreases for the NLC group, although the $9 \%$ reduction is more moderate relative to the drop in labor unit costs. LCCs took advantage of the same technologies and productivity improvements to lower their nonlabor unit costs by 5\%, maintaining a 1 cent/ASM gap in this cost metric in 2006.

Our analysis of the changes in unit costs for individual airlines in each carrier group revealed that the NLCs which went through the bankruptcy process realized the greatest decreases in labor unit costs. Among LCCs, the changes in labor unit costs were mixed, as the oldest LCC Southwest saw its labor unit costs increase while the less mature and more rapidly growing JetBlue and AirTran were able to report a decrease in labor unit costs over the 2001-2006 period. Finally, we explored the relationships between stage length and unit cost measures of all categories. Every airline in our dataset showed an increase in stage length between 2000 and 2006, and in many cases the move to longer flights correlated extremely well with lower unit cost metrics.

Driven by competitive forces as well as exogenous events, Network Legacy Carriers have used a variety of strategies to reduce unit costs since 2001. As shown in our analysis, there are clear signs of cost convergence in the US airline industry between NLCs and LCCs. At the same time, there remains a gap in unit costs between the two groups, explained in large part by the difference in non-labor unit costs. This gap is in many respects structural - while NLCs compete on price with LCCs in the US domestic market, they still provide a very different air transportation service as part of their much 
larger international hub networks. By operating these networks, NLCs provide on-line connections from small US cities to the remote international destinations, something that no LCC can provide. The operating costs of providing such extensive networks are inherently greater for many reasons, suggesting that there exists a structural unit cost gap between NLCs and LCCs that simply cannot be reduced much further.

Despite the improvements in cost efficiency among NLCs identified in our analysis, the US industry still faces substantial challenges. The next round of labor negotiations may be the most important milestone in the U.S. airline industry since deregulation. As demonstrated in our analysis, airline employees have helped contribute to the short-term recovery of the industry. Finding a new model for compensation that is durable and works to address the cyclicality of the industry will be critical. Just as important will be the efforts of management to identify non-labor cost savings that can be sustained as networks and operating models are reconfigured. 


\section{References}

Aviation Daily, US Industry Traffic Market Share, Eclat Consulting, McGraw-Hill, Friday, August 18, 2006.

Doganis, R. (2006) The Airline Business, Second Edition, Routledge. .

Holloway, S. (2003) Straight and Level: Practical Airline Economics, Ashgate.

Jordan, W.A. (1982) Performance of Regulated Canadian Airlines in Domestic and

Transborder Operations, Consumer and Corporate Affairs Report, Canada.

Meyer, J.R., Oster, C.V., Morgan, I.P., Berman, B.A., and Strassman, D.L. (1981) Airline Deregulation: The Early Experience, Auburn House.

Morrison, S., and Winston, C. (1986) The Economic Effects of Airline Deregulation, The Brookings Institution, Washington, DC.

Oum, T.H. and Yu, C. (1998) Winning Airlines: Productivity and Cost Competitiveness of the World's Major Airlines, Kluwer Academic Publishers, Transportation Research, Economics and Policy.

United States Government Accountability Office (2004), Commercial Aviation, Legacy Airlines Must Further Reduce Costs to Restore Profitability, GAO-04-836, August. 


\section{FIGURES}

Figure 1: Form $41 \mathrm{P}$ and $\mathrm{B}$ schedules

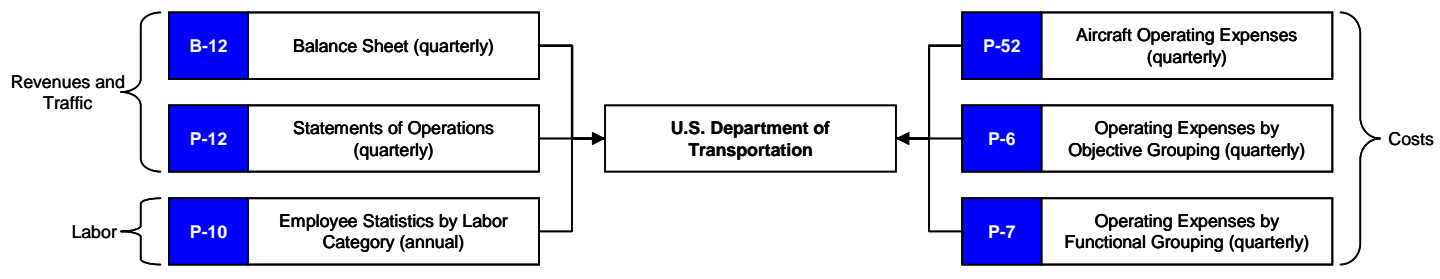

Figure 2: Adjusting Unit Costs (CASM)

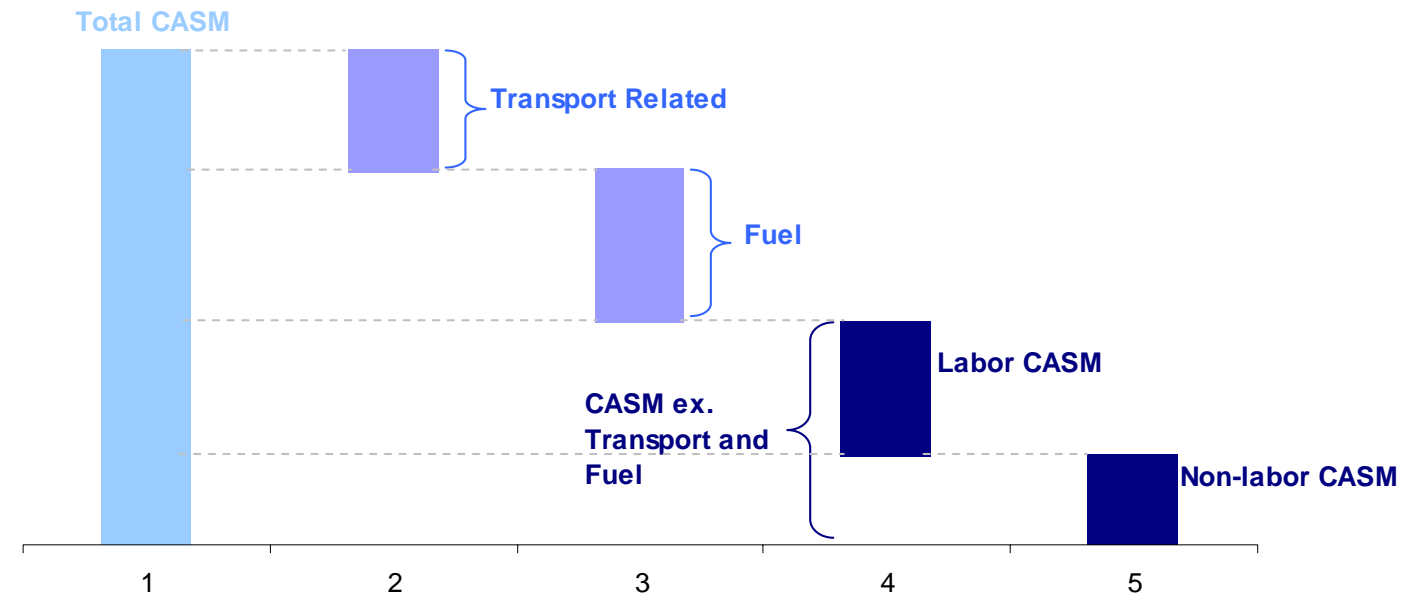

Figure 3: Aggregate Comparison: Total CASM

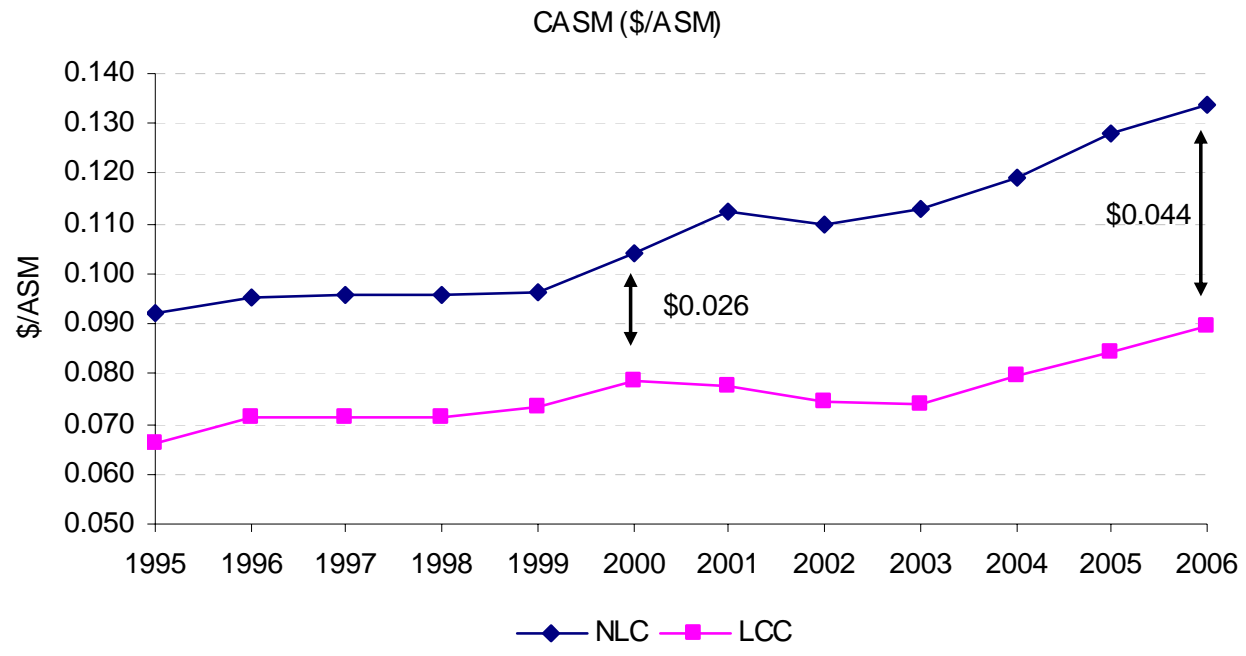


Figure 4: Aggregate comparison: Ex-transport related CASM

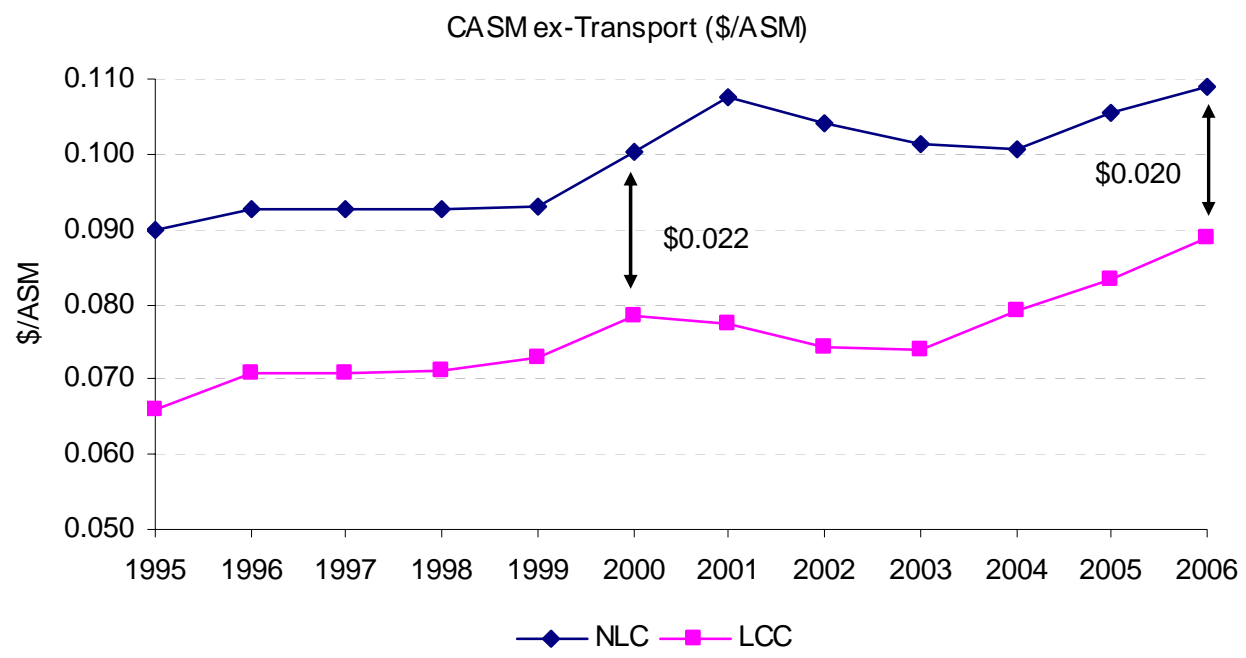

Figure 5: Aggregate Comparison CASM $_{\text {exTF }}$ (ex transport-related and fuel)

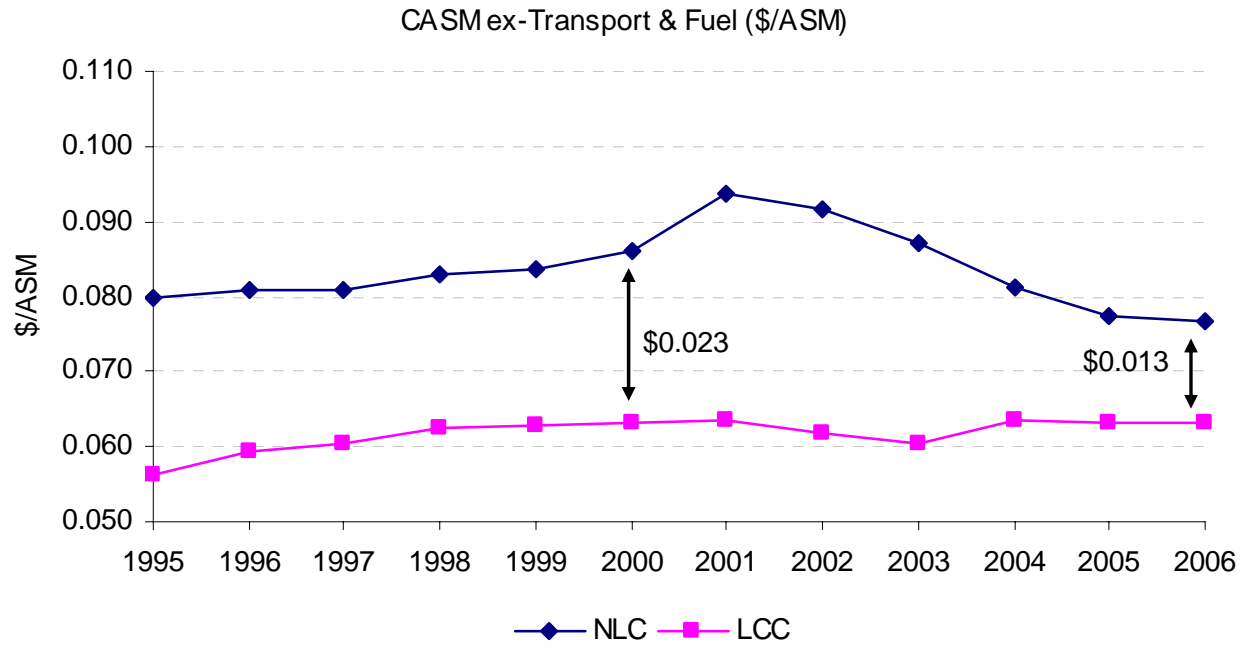


Figure 6: Aggregate Comparison: Non-labor CASM exTF

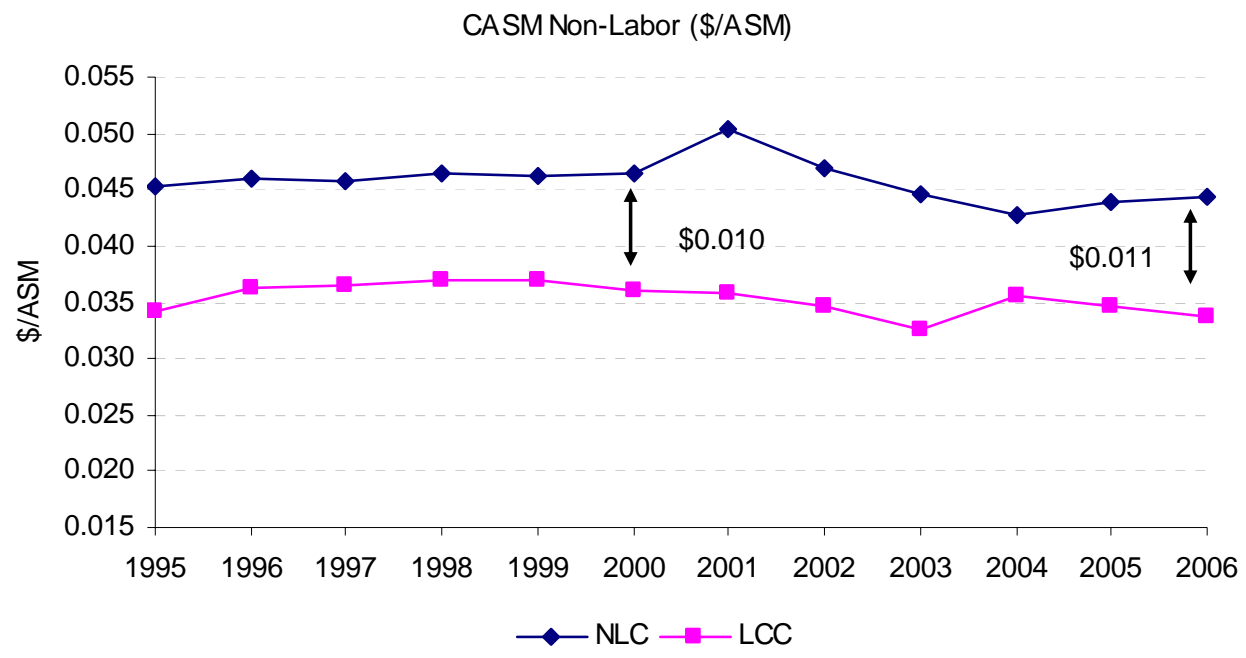

Figure 7: Aggregate Comparison: Labor CASM exTF

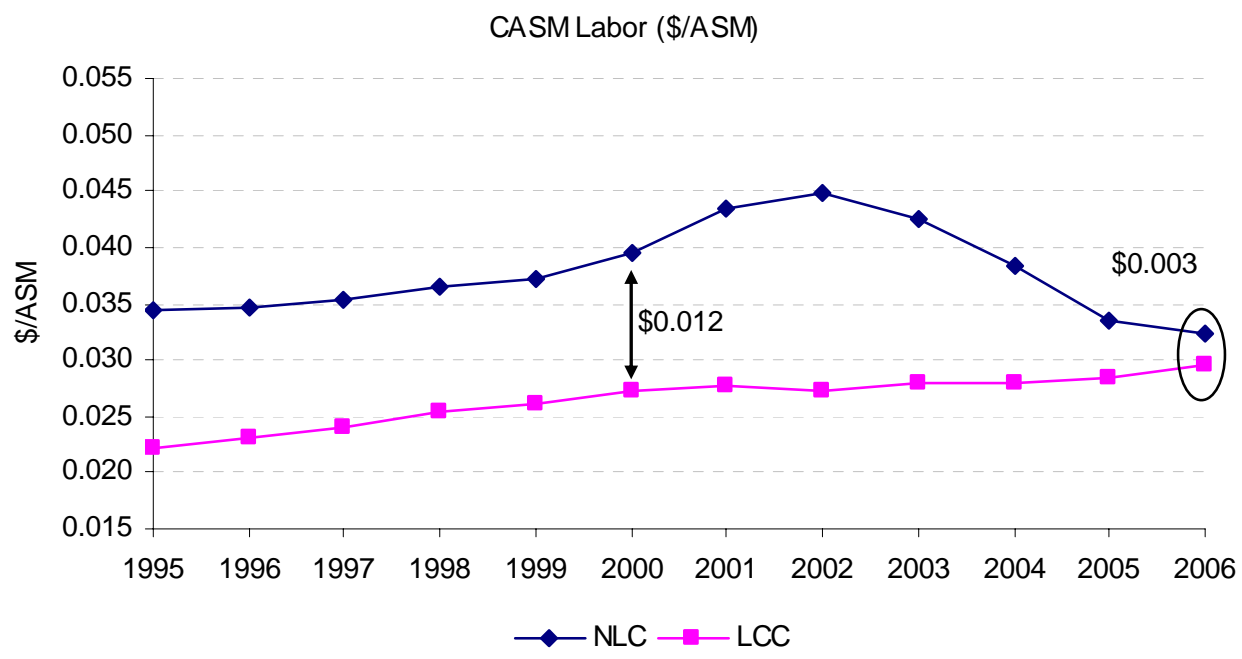


Figure 8 Aggregate comparison: NLC CASM \% breakdown

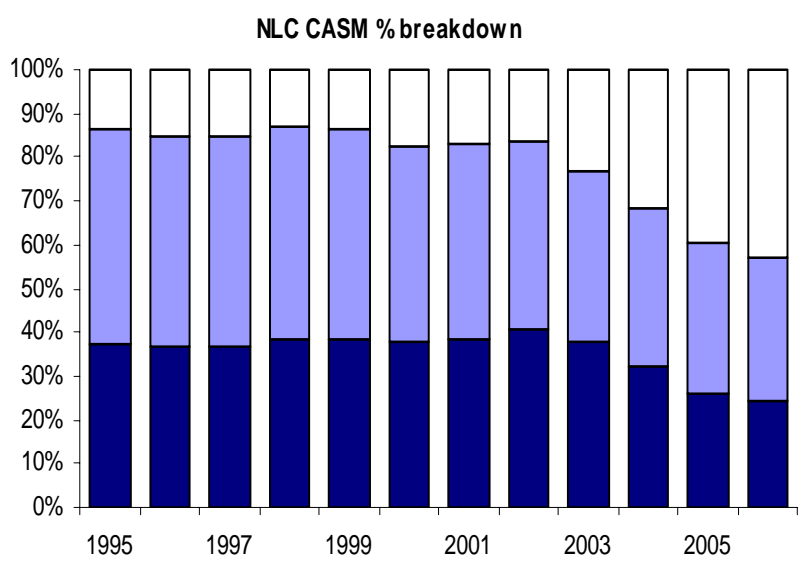

- CASM Labor (\$/ASM) ם CASM Non-Labor (\$/ASM) $\square$ Fuel \& Tr. Exp.

Figure 9: Aggregate comparison: LCC CASM \% breakdown

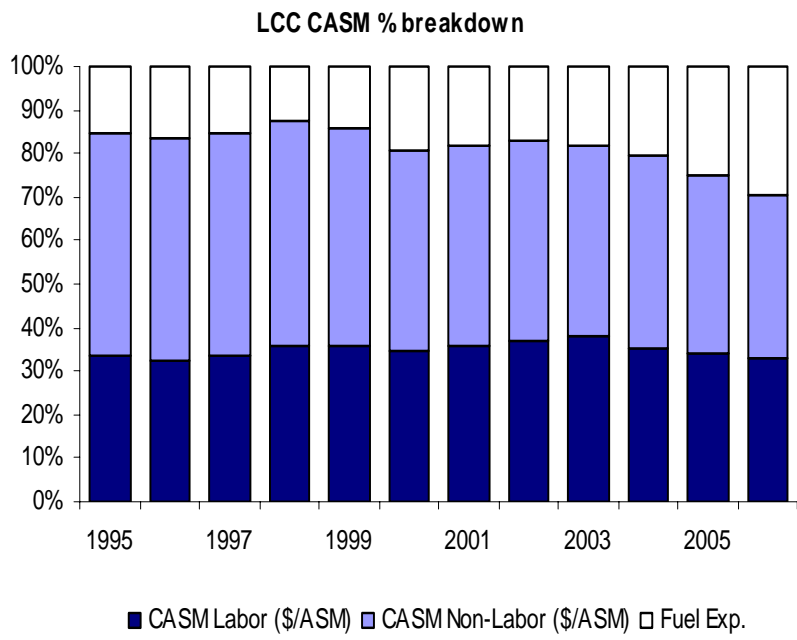


Figure 10: Change in CASMexTF 2001 to 2006

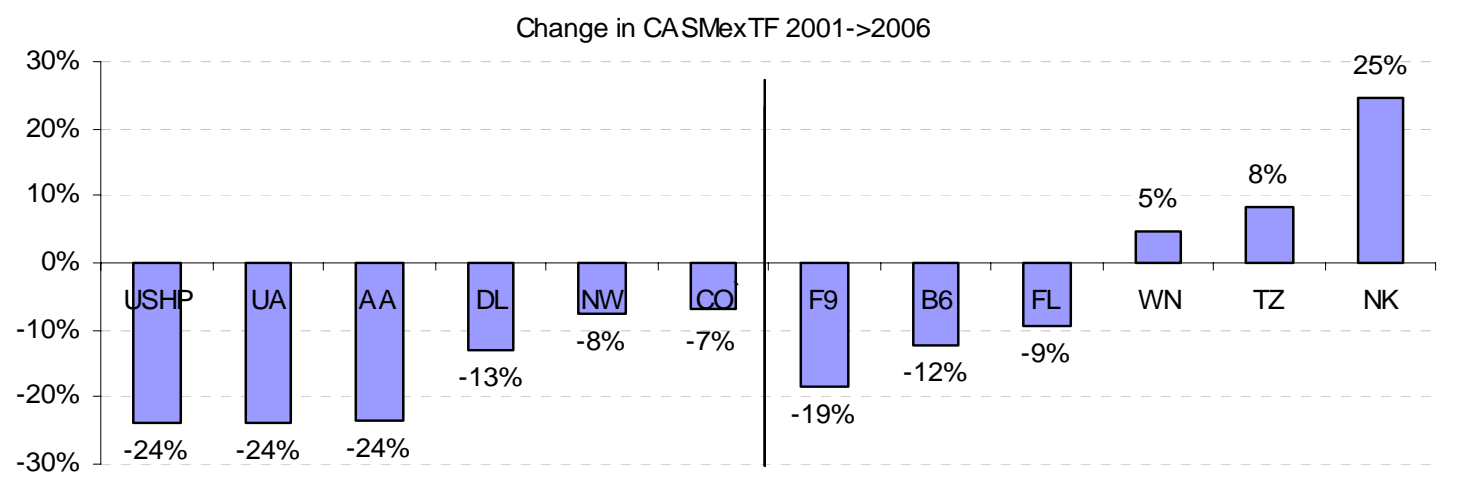

Figure 11: CASMexTF Rankings in 2006

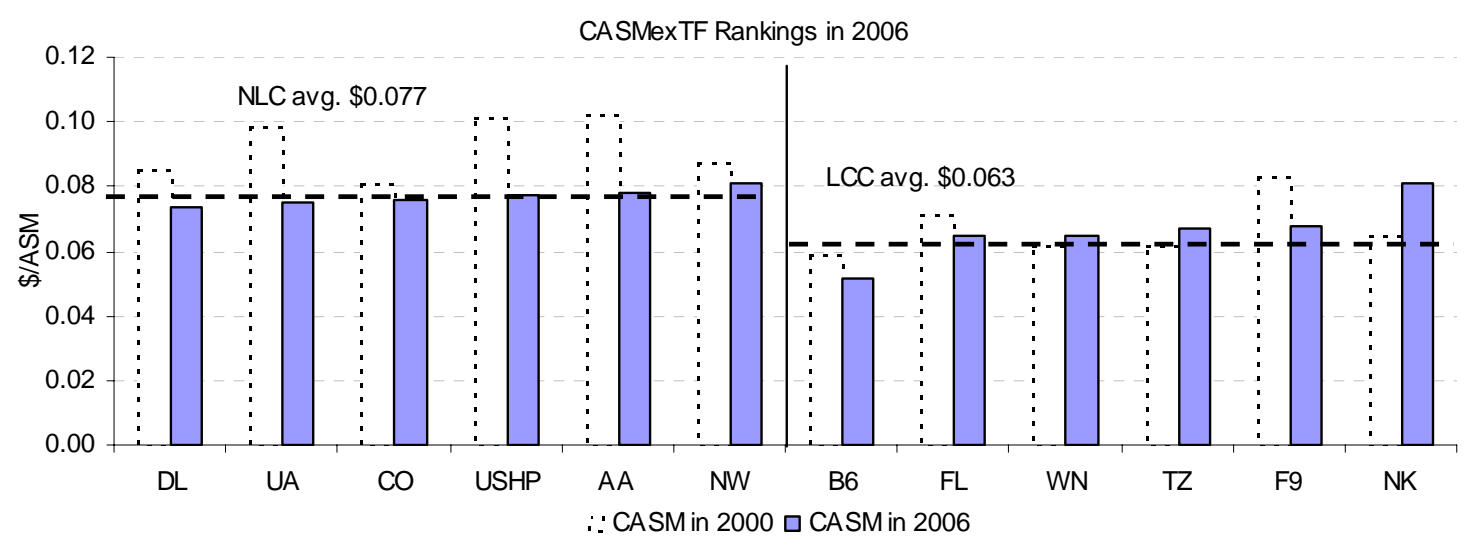

Figure 12: Change in Labor CASM 2001 to 2006

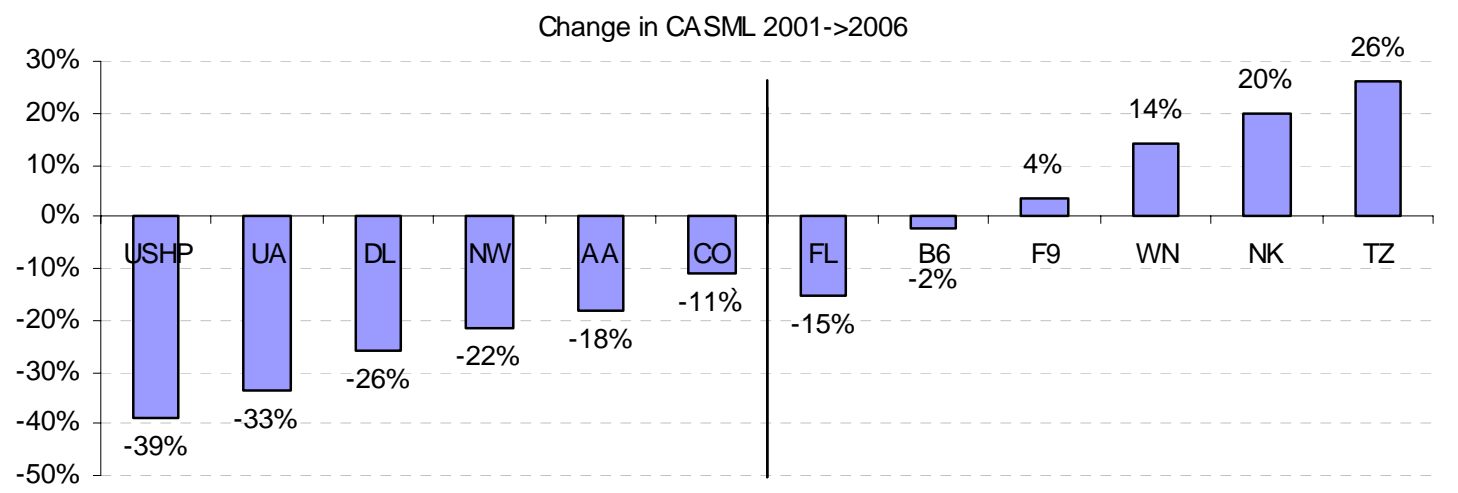


Figure 13: Change in non-Labor CASM 2001 to 2006

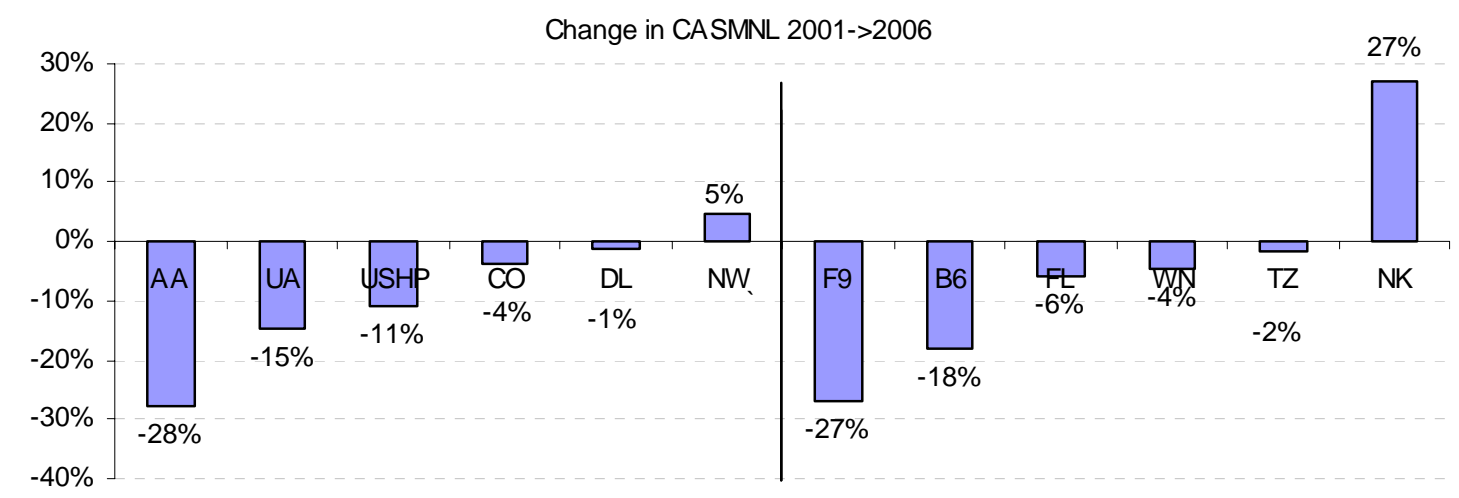

Figure 14: CASMexTF vs. Stage Length

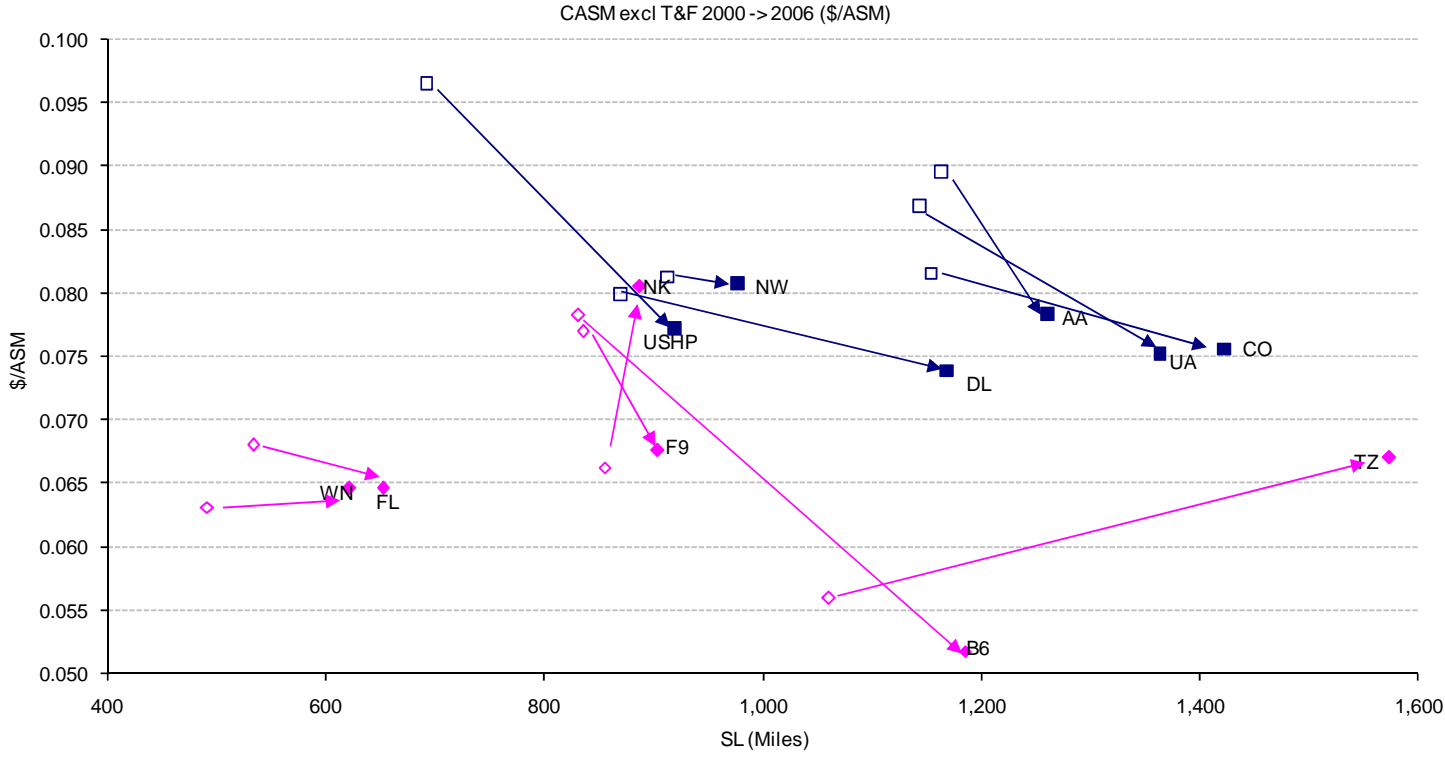

口NLC2000 $=$ NLC2006 $\diamond L C C 2000 \bullet$ LCC2006 


\section{TABLES}

Table 1: Breakdown of US Carriers into NLC and LCC groups

Network Legacy Carriers Low Cost Carriers

America West and US Airways (HP + US) JetBlue (B6)

American Airlines (AA)

Frontier (F9)

Continental (CO)

Airtran (FL)

Delta (DL)

American Trans Air (TZ)

Northwest (NW)

Southwest (WN)

United Airlines (UA)

Spirit Airlines (NK) 